\title{
Low-Temperature III-V Direct Wafer Bonding Surface Preparation Using a UV-Sulfur Process
}

\author{
MICHAEL J. JACKSON, ${ }^{1,2}$ LI-MIN CHEN, ${ }^{1}$ ANKIT KUMAR, ${ }^{1}$ \\ YANG YANG ${ }^{1}$ and MARK S. GOORSKY ${ }^{1}$ \\ 1.-Department of Materials Science and Engineering, UCLA, 410 Westwood Plaza, \\ 3111 Engineering V, Los Angeles, CA 90095-1595, USA. 2.-e-mail: mrmikejackson@ucla.edu
}

\begin{abstract}
A technique for direct wafer bonding of III-V materials utilizing a dry sulfur passivation method is presented. Large-area bonding occurs for GaAs/GaAs and $\mathrm{InP} / \mathrm{InP}$ at room temperature. Bulk fracture strength is achieved after annealing $\mathrm{GaAs} / \mathrm{GaAs}$ at $400^{\circ} \mathrm{C}$ and $\mathrm{InP} / \mathrm{InP}$ at $300^{\circ} \mathrm{C}$ for times less than $12 \mathrm{~h}$ without large compressive forces. X-ray photoelectron spectroscopy measurements of the treated, bonded, and subsequently delaminated surfaces of GaAs/ GaAs confirm that sulfide is present at the interface and that the oxide components show a reduced concentration when compared with samples treated with only an oxide etch solution.
\end{abstract}

Key words: Wafer bonding, materials integration, III-V, sulfur passivation

\section{INTRODUCTION}

Direct wafer bonding promotes the integration of heterogeneous semiconductor materials without the constraints of lattice constant or crystal structure mismatch for epitaxially grown layers. Wafer bonding with an intermediate bonding layer such as $\mathrm{SiO}_{2}{ }^{1}$ or silicon nitride ${ }^{2}$ can produce semiconductoron-insulator structures with almost any combination of materials for applications requiring electrical isolation or for composite growth substrates. ${ }^{3}$ Wafer-bonded optoelectronic devices such as latticemismatched solar cells require the bonded interface to be transparent and conductive, such that the interface must be free of insulating layers or opaque metallic layers. III-V surfaces such as GaAs suffer from unfavorable native oxides that are difficult to eliminate, and the properties of the bonded interfaces are dominated by unfavorable mechanical and electronic properties. ${ }^{4}$ Often, annealing at elevated temperatures $\left(>600^{\circ} \mathrm{C}\right)$ for times in excess of $30 \mathrm{~min}$ with large compressive forces must be employed to break up the interfacial oxide layer to form better contact between the III-V layers. ${ }^{5}$ These harsh processing conditions can be undesirable for processed samples with a limited thermal process

(Received May 3, 2010; accepted October 4, 2010;

published online October 23, 2010) budget. Lian et al. demonstrated that temperatures of at least $550^{\circ} \mathrm{C}$ for $1 \mathrm{~h}$ are required for $\mathrm{AlGaAs} /$ $\mathrm{GaAs} / \mathrm{GaN}$ heterojunction bipolar transistors (HBTs) formed by wafer fusion methods, yet that the HBTs suffer gain degradation at annealing temperatures above $450^{\circ} \mathrm{C}{ }^{6}$ A surface treatment prior to bonding that reduces the inclusion of unfavorable oxides in the interface could reduce the need for high-temperature processing. However, this surface treatment must also maintain a low surface roughness that is compatible with subsequent bonding. Reduction of surface oxides ${ }^{7}$ and maintenance of low roughness surface ${ }^{8}$ are also important for development of III-V gate dielectrics.

The treatment of III-V surfaces with sulfur or sulfide-containing solutions is known to improve the surface electronic properties for Schottky contacts and heterojunction bipolar transistors, primarily due to replacement of surface oxide with a thin sulfide layer. ${ }^{9,10}$ Various sulfide solution passivation methods have been reported for direct bonding, including thiourea in $\mathrm{NH}_{4} \mathrm{OH},{ }^{11}(\mathrm{NH} 4)_{2} \mathrm{~S},{ }^{12}$ and $\left(\mathrm{NH}_{4}\right)_{2} \mathrm{~S}$ in $t$-butanol, ${ }^{13}$ with the latter treatment shown to improve the interfacial conductivity of wafer-bonded $p$-GaAs/ $n$-InP over an $\mathrm{HCl}$ treatment. In this study, modifications to a III-V surface passivation technique first described by Ashby et al. ${ }^{14}$ are performed to achieve high-strength bonding for $\mathrm{GaAs} / \mathrm{GaAs}$ and $\mathrm{InP} / \mathrm{InP}$ after low-temperature 
$\left(<400^{\circ} \mathrm{C}\right)$ annealing. The method utilizes elemental sulfur vapor activated by ultraviolet illumination under high vacuum to form a thin sulfide layer on the III-V surface, which through the addition of a step to remove excess physisorbed sulfur, yields a smooth hydrophobic surface suitable for direct wafer bonding.

\section{EXPERIMENTAL PROCEDURES}

Passivation and direct bonding experiments were performed on epiready Si-doped (001) $n$-GaAs with a carrier concentration of $1.2 \times 10^{18} \mathrm{~cm}^{-3}$ and S-doped $n$-InP with a carrier concentration of $5 \times 10^{18} \mathrm{~cm}^{-3}$. The wafers were degreased in acetone and isopropyl alcohol for $5 \mathrm{~min}$, rinsed in deionized water, and subjected to 200 mTorr oxygen plasma treatment for $1 \mathrm{~min}$ at a power of $200 \mathrm{~W}$. The oxidized surface was etched in 1:10 $\mathrm{NH}_{4} \mathrm{OH}: \mathrm{H}_{2} \mathrm{O}$ for 2 min for GaAs and 1:10 HF: $\mathrm{H}_{2} \mathrm{O}$ for 2 min for InP, then rinsed in water and dried under $\mathrm{N}_{2}$. After the surface oxide removal, the wafers were loaded into a vacuum chamber which contains a mediumpressure $\mathrm{Hg}$-vapor ultraviolet light source, a temperature-controlled surface, and a crucible containing elemental sulfur power. At a chamber pressure of $3 \times 10^{-6}$ Torr to $10 \times 10^{-6}$ Torr, the UV lamp illuminated the bonding surfaces, and the temperature of the sulfur powder and samples were increased to $45^{\circ} \mathrm{C}$ to $60^{\circ} \mathrm{C}$, as measured by a thermocouple. Within this temperature range, the vapor pressure of sulfur ranges between $10^{-5}$ Torr and $10^{-4}$ Torr, causing some of the powder to sublime to vapor in the vacuum chamber. ${ }^{15}$ The sulfur vapor becomes reactive under UV illumination through cleavage of the $S_{8}$ ring into free radicals which can react with the III-V surface to form a thin passivation layer. ${ }^{14,16}$ The bonding surfaces were exposed to this sulfur vapor and UV light for $5 \mathrm{~min}$. In some cases, to determine whether subsequent processing was necessary to maintain a surface free of excess sulfur deposits, the sulfur source was removed from the chamber and the samples were exposed to UV illumination again while being heated to $75^{\circ} \mathrm{C}$ for 5 min. After the treatment, the surfaces exhibit hydrophobic behavior. The samples were aligned face to face with bonding initiated by applying pressure at the center and allowing the bonding front to propagate to the wafer edges. The bonded samples were then annealed at $200^{\circ} \mathrm{C}$ to $400^{\circ} \mathrm{C}$ (with a ramp rate of $1.5^{\circ} \mathrm{C} / \mathrm{min}$ ) and only $5 \mathrm{kPa}$ to $10 \mathrm{kPa}$ compression for $1 \mathrm{~h}$ to $24 \mathrm{~h}$. Reference bonded samples were prepared by bonding immediately after the oxide removal etch.

The surface morphology of processed samples was monitored by atomic force microscopy (AFM). Bonding area was monitored by transmission infrared (IR) imaging, and bond strength was determined using the razor crack opening method with a $240 \mu \mathrm{m}$ razor blade thickness. ${ }^{17}$ Surface characterization was performed using x-ray photoelectron spectroscopy (XPS) with monochromatic Al $\mathrm{K}_{\alpha}$ radiation $(1486.6 \mathrm{eV})$ and $20 \mathrm{eV}$ band pass energy. XPS measurements were performed with a take-off angle of $20^{\circ}$ between the surface and the detector to enhance the signal from the bonding surface. Arsenic $2 p_{3 / 2}$ and gallium $2 p_{3 / 2}$ spectra were analyzed for the presence of core level chemical shifts for oxides and sulfides, and the $\mathrm{S} 2 \mathrm{p} / \mathrm{Ga} 3 \mathrm{~s}$ region was used to confirm the presence of sulfur bonded at the surface. Peak deconvolution was performed with the free XPSPEAK software program and involved subtraction of a Shirley background and curve-fitting with a sum of $70 \%$ Gaussian and 30\% Lorentzian lines.

\section{RESULTS AND DISCUSSION}

Initial bonding trials followed the passivation technique described by Ashby et al. ${ }^{14}$ such that the surfaces were contacted after the UV illumination and sulfur passivation step. The result was always a poor bond, which delaminated upon a $300^{\circ} \mathrm{C}$ anneal of $12 \mathrm{~h}$. The debonded sample surface was yellow, and exhibited an uneven surface roughness, as shown by AFM in Fig. 1a. This presumably is the

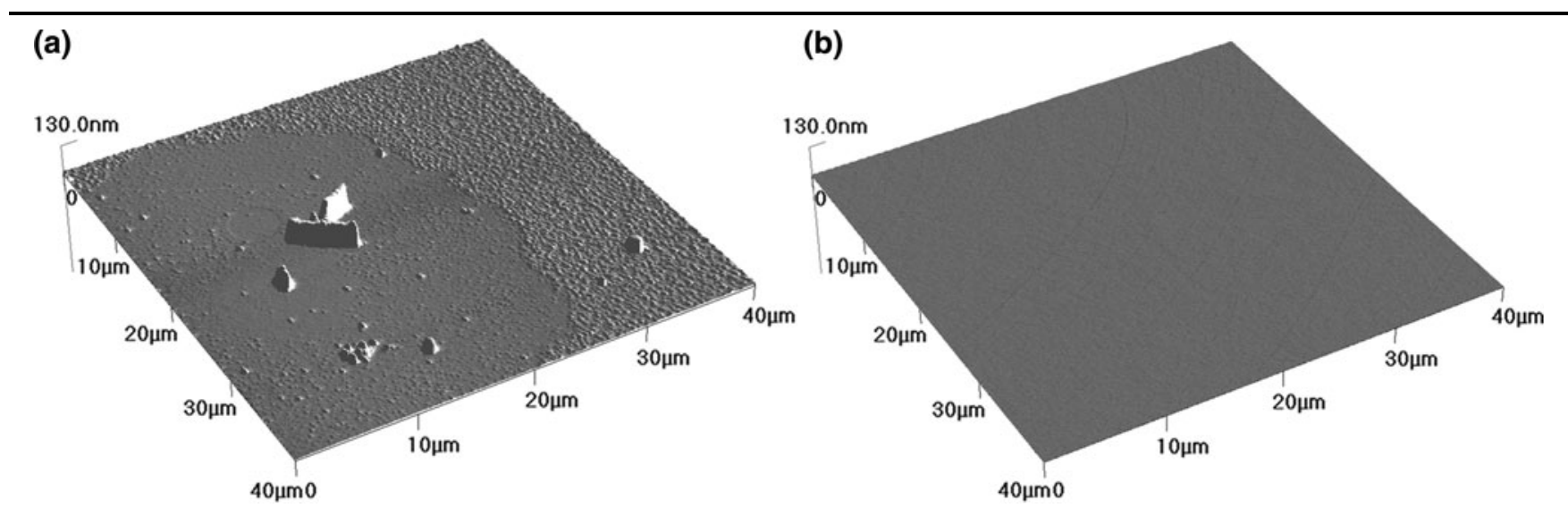

Fig. 1. AFM scan $(40 \mu \mathrm{m} \times 40 \mu \mathrm{m})$ of (a) debonded GaAs wafer showing nonuniform surface roughness from excess elemental sulfur at the interface, (b) UV-sulfur processed GaAs sample showing a clean surface with RMS roughness of $2.3 \AA$. 


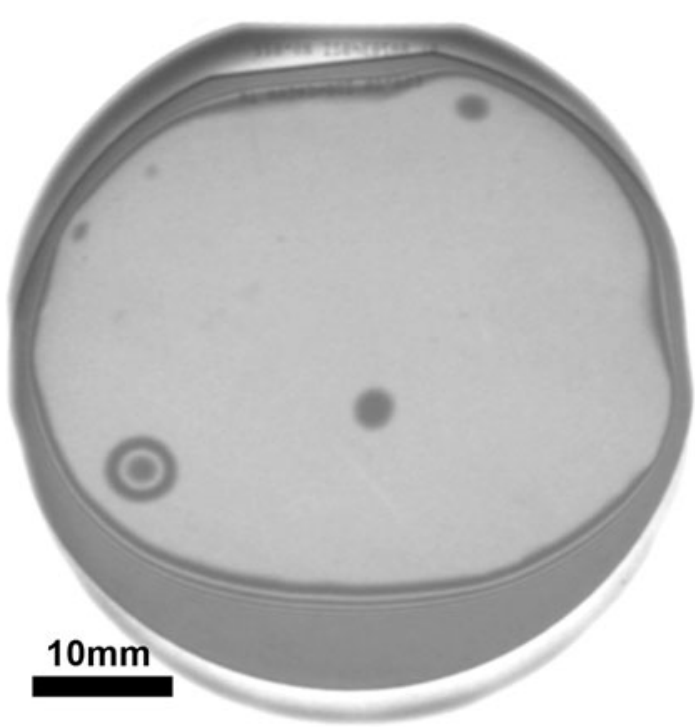

Fig. 2. Transmission IR image of UV-S-bonded GaAs/GaAs, annealed for $1 \mathrm{~h}$ at $400^{\circ} \mathrm{C}$.

result of elemental sulfur being deposited along with the UV-activated sulfur species, and while elemental sulfur was not much of a concern for applications of passivation, it does have a highly adverse effect in wafer bonding. To minimize this excess sulfur at the surface in favor of only a reacted sulfide or chemisorbed S layer, all subsequent samples were also heated in vacuum to $75^{\circ} \mathrm{C}$ under UV light without the sulfur source after the initial sulfur deposition. It is postulated that physisorbed sulfur will sublimate under these conditions while chemisorbed sulfide will remain. ${ }^{15,18}$ Figure $1 b$ shows an AFM image of GaAs treated with this new procedure, referred to as UV-S, showing that the process maintains the original surface roughness of less than $3 \AA$ root-mean-square (RMS) roughness that is suitable for direct bonding. Further investigation is underway into the kinetics of the removal of physisorbed sulfur from the surface for further process optimization.

The bonded area of UV-sulfur- and $\mathrm{NH}_{4} \mathrm{OH}$ treated reference samples were monitored by transmission IR after bonding and after annealing. Figure 2 shows an IR image of UV-S-bonded GaAs/ GaAs 50-mm wafers with annealing for $1 \mathrm{~h}$ at $400^{\circ} \mathrm{C}$. There were five interfacial voids initially present upon bonding. Subsequent annealing for any time length did not cause them to expand or new voids to form. Crack opening tests were performed on $\mathrm{GaAs} / \mathrm{GaAs}$ bonded samples with $510 \mu \mathrm{m}$ wafer thicknesses and annealing for $12 \mathrm{~h}$ at $300^{\circ} \mathrm{C}$. The UV-S-treated sample had a crack length of $18 \pm 0.5 \mathrm{~mm}$, while the reference $\mathrm{NH}_{4} \mathrm{OH}$ sample had a crack length of $20 \pm 0.5 \mathrm{~mm}$. Using a Young's modulus value for $\mathrm{GaAs}$ of $121.3 \mathrm{GPa}$ for the [110] bending axis yields a bond strength of $830 \pm 90 \mathrm{~mJ} / \mathrm{m}^{2}$ for the UV-S sample and $540 \pm 50 \mathrm{~mJ} / \mathrm{m}^{2}$ for the $\mathrm{NH}_{4} \mathrm{OH}$ etched sample. ${ }^{19}$ The value for the $\mathrm{NH}_{4} \mathrm{OH}$

\section{S 2p Ga 3s}

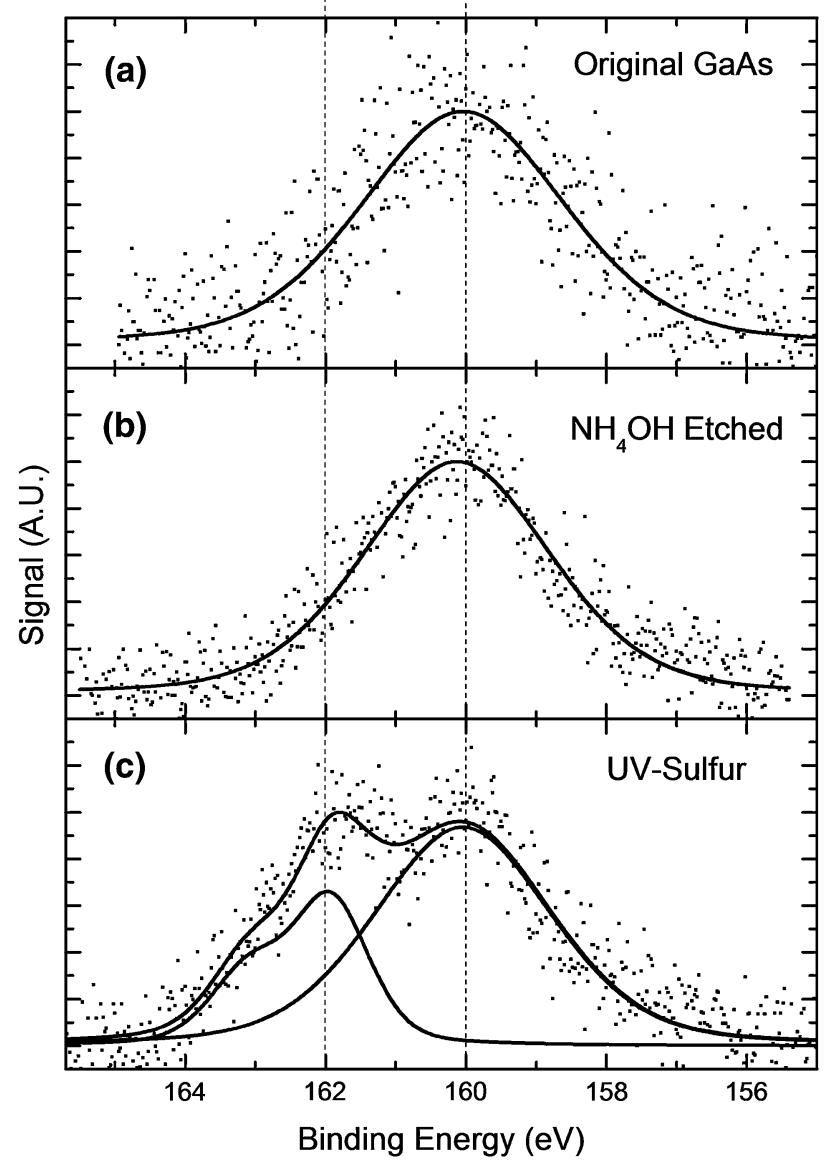

Fig. 3. The Ga 3s XPS region for (a) unprocessed GaAs, (b) after $\mathrm{NH}_{4} \mathrm{OH}$ etching, and (c) after the UV-sulfur process.

etched sample is comparable to the value of $425 \pm 80 \mathrm{~mJ} / \mathrm{m}^{2}$ for GaAs etched in $\mathrm{HCl}$ and bonded at $300^{\circ} \mathrm{C}$ for $8 \mathrm{~h}^{20}$ The measured bond strength of the UV-S sample is close to the bulk fracture energy for $\mathrm{GaAs}$ of $900 \pm 100 \mathrm{~mJ} / \mathrm{m}^{2}$ as measured by cleaning and bonding in ultrahigh vacuum (UHV) ${ }^{21}$ and to the value of $750 \mathrm{~mJ} / \mathrm{m}^{2}$ reported for $\mathrm{HCl}$ etched GaAs annealed at $400^{\circ} \mathrm{C}$ for $1 \mathrm{~h}$ and $600^{\circ} \mathrm{C}$ for 30 min. ${ }^{22}$ Annealing UV-S-bonded GaAs pairs at $400^{\circ} \mathrm{C}$ for $12 \mathrm{~h}$ resulted in an improvement in bond strength to that of bulk fracture energy such that the crack front causes bulk fracture through one of the wafers rather than propagating along the bonded interface. Bonded pairs of InP/InP were also prepared by the UV-S treatment, and razor crack measurements indicated that bulk bonding strength is achieved with annealing at $300^{\circ} \mathrm{C}$ for $2 \mathrm{~h}$.

The XPS scan around the binding energy of $160 \mathrm{eV}$, where the core levels of Ga $3 \mathrm{~s}$ and $\mathrm{S} 2 \mathrm{p}$ partially overlap, is shown in Fig. 3 for unprocessed, $\mathrm{NH}_{4} \mathrm{OH}$-etched, and UV-sulfur samples. The Ga 3s peak is present at $160 \mathrm{eV}$ for all surface treatments, while the UV-sulfur-treated surface also shows the S $2 p$ doublet with $2 p_{3 / 2}$ located at $162 \mathrm{eV}$. This binding energy value is consistent with a sulfide 

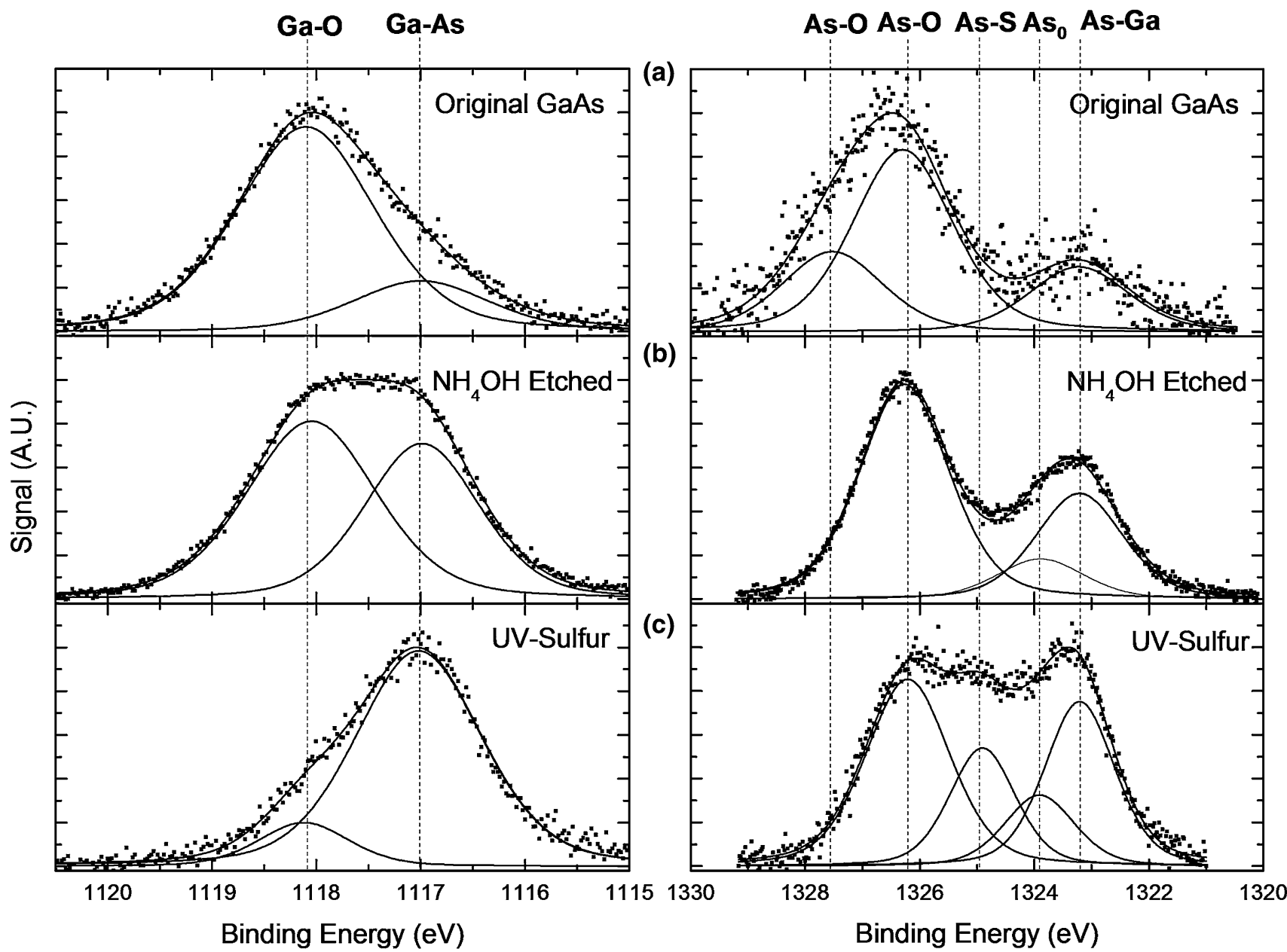

Fig. 4. Ga $2 p_{3 / 2}$ and As $2 p_{3 / 2}$ XPS region for (a) unprocessed GaAs, (b) after $\mathrm{NH}_{4} \mathrm{OH}$ etching, and (c) after the UV-sulfur process. In (c), the Ga $2 p_{3 / 2}$ shoulder peak on the left is likely associated with both Ga-S and residual Ga-O.

rather than bulk sulfur, as the latter is expected at $164 \mathrm{eV}^{23}$ This indicates that the sulfur vapor is indeed chemisorbed to form a sulfide at the surface.

Some reports about surface passivation or of wafer bonding preparation which use XPS characterization fail to state the take-off angle that would reveal how well tuned the measurement is to the top surface layer. For studying the chemical state of two surfaces being contacted to initiate a direct wafer bond, it is important to select a core level spectra which has a small sampling depth and to have measurable core level chemical shifts for different bonding states. The As $2 p_{3 / 2}$ peaks near $1323 \mathrm{eV}$ and $\mathrm{Ga} 2 \mathrm{p}_{3 / 2}$ peaks near $1117 \mathrm{eV}$ excited with $\mathrm{Al} \mathrm{K}_{\alpha}$ radiation and taken at $20^{\circ}$ grazing angle are very surface sensitive, with an information depth of around $8 \AA$ and $12 \AA$, respectively. ${ }^{18}$ Figure 4 shows the deconvolution of the As $2 p_{3 / 2}$ and $\mathrm{Ga} 2 \mathrm{p}_{3 / 2}$ spectra for unprocessed, $\mathrm{NH}_{4} \mathrm{OH}$-etched, and UV-sulfur samples. The spectra for unprocessed GaAs (Fig. 4a) is dominated by oxidized components with As $2 \mathrm{p}_{3 / 2}$ showing $3 \mathrm{eV}$ and $4.3 \mathrm{eV}$ shifted peaks attributed to $\mathrm{As}_{2} \mathrm{O}_{3}$ and $\mathrm{As}_{2} \mathrm{O}_{5}$ and $\mathrm{Ga} 2 \mathrm{p}_{3 / 2}$ showing a $1.1 \mathrm{eV}$ shifted peak attributed to $\mathrm{Ga}_{2} \mathrm{O}_{3}$. These chemical shift values are marginally lower than those reported by Arabasz et al. ${ }^{18}$ of $3.3 \mathrm{eV}$ and $4.5 \mathrm{eV}$ for As-O $2 \mathrm{p}_{3 / 2}$ and $1.2 \mathrm{eV}$ for Ga-O $2 \mathrm{p}_{3 / 2}$, but the overall peak trends are consistent. The peak area ratios of As-O to As-Ga and Ga-O to Ga-As are each about 4:1 on the unprocessed sample. For the $\mathrm{NH}_{4} \mathrm{OH}$-etched sample (Fig. 4b), the $\mathrm{As}_{2} \mathrm{O}_{5}$ peak is eliminated, and also a new peak shifted by $0.7 \mathrm{eV}$ must be added to maintain good fitting. This minor peak is attributed to elemental arsenic. The signal ratio of oxidized to bulk components after the etch is reduced to $2: 1$ for As $2 p_{3 / 2}$ and $1: 1$ for Ga $2 p_{3 / 2}$, indicating that either the etching solution did not remove all the oxide or that some reoxidation occurred after removal from the solution. The XPS measurement of the UV-sulfurtreated sample (Fig. 4c) shows that the As-O to As-Ga ratio is lowered to $1.3: 1$, and there is the appearance of a new peak shifted by $1.7 \mathrm{eV}$ with an area relative to As-Ga of 0.67 . This $1.7 \mathrm{eV}$ shifted peak is assigned to As-S formed during the UV-sulfur exposure, which is close to the $1.8 \mathrm{eV}$ value reported by Ashby et al. for passivation with UV-activated sulfur vapor, ${ }^{16}$ and lower than the $2.13 \mathrm{eV}$ reported by Arabasz et al. for aqueous 
$\left(\mathrm{NH}_{4}\right)_{2} \mathrm{~S}$ treatment. ${ }^{18}$ The Ga $2 \mathrm{p}_{3 / 2}$ spectra of the UV-S sample shows a reduction in the high binding energy signal to a small shoulder that, if attributed only to Ga-O, results in a ratio of 1:7 compared with the Ga-As signal. The Ga-S peak is reported to be located $0.7 \mathrm{eV}$ from Ga-As, so the shoulder on the Ga $2 \mathrm{p}_{3 / 2}$ peak is likely a mixture of $\mathrm{Ga}-\mathrm{O}$ and $\mathrm{Ga}-\mathrm{S}$ that overlap too much to deconvolute accurately into separate peaks.

XPS measurements confirm that it is difficult to attain complete elimination of an oxide layer from a GaAs bonding surface if processed and transported in ambient air. Despite this, the spectra from the UV-sulfur sample after $\mathrm{NH}_{4} \mathrm{OH}$ etching shows significantly reduced surface oxidation compared with a sample etched with $\mathrm{NH}_{4} \mathrm{OH}$ alone, especially for the Ga $2 p_{3 / 2}$. Exposure to sulfur vapor under UV illumination is not expected to etch the surface as would a $\left(\mathrm{NH}_{4}\right)_{2} \mathrm{~S}$ solution, so this indicates that the sulfide layer may inhibit the reaction between physisorbed oxygen and GaAs in the formation of an oxide. Zavadil et al. ${ }^{16}$ reports that the passivation effect of UV-activated sulfur vapor is further improved if etching and loading of GaAs are kept in a $\mathrm{N}_{2}$ environment to prevent oxidation before the sulfide layer can form on the surface. However, the current results of using UV-sulfur for wafer bonding show that the presence of the sulfide layer can improve the bond strength even without the complete absence of oxide.

\section{CONCLUSIONS}

Bonded samples of GaAs/GaAs treated with the UV-sulfur process have been produced and exhibit large-area bonding, achieving bulk bond strength with a $400^{\circ} \mathrm{C}$ anneal. The UV-S process has also been employed to bond InP/InP pairs, which attain bulk fracture strength with a $300^{\circ} \mathrm{C}$ anneal. The process is able to maintain a clean surface without roughening, through heating of the surface to $75^{\circ} \mathrm{C}$ with UV illumination under vacuum to remove excess sulfur. The combination of the high bond strength and the XPS data indicates that the surface heating/UV illumination helps remove excess sulfur at the surface and promotes effective bonding. The bonded wafers do not show the appearance of interfacial voids with annealing and do not require large compressive forces to form the bond. The UV-S process changes the chemical state of the bonding surface from being dominated by $\mathrm{As}-\mathrm{O}$ and $\mathrm{Ga}-\mathrm{O}$ species to having significantly less Ga-O, a mixture of As-S and As-O, and possibly some Ga-S bonds. The presence of III-V oxides at a wafer-bonded interface is often associated with low bond strength $^{22}$ and a large barrier to electrical conduction, ${ }^{24}$ while the UV-S method shows that sulfur passivation techniques can yield improvements in bond strength. Processing under a controlled atmosphere such as nitrogen could further improve the technique. Homogeneous GaAs/GaAs bonding serves as a route towards heterogeneous combinations such as GaAs/InP through better understanding of the problematic GaAs bonding surface, without added complications such as band alignment, compositional alloying, and thermal expansion mismatch. Our efforts are now focused on investigating the electrical properties of sulfur-bonded interfaces, and the role that such low-temperature bonding methods can have in integrating lattice-mismatched structures.

\section{OPEN ACCESS}

This article is distributed under the terms of the Creative Commons Attribution Noncommercial License which permits any noncommercial use, distribution, and reproduction in any medium, provided the original author(s) and source are credited.

\section{REFERENCES}

1. J.B. Lasky, Appl. Phys. Lett. 48, 78 (1986).

2. S. Hayashi, M. Goorsky, A. Noori, and D. Bruno, J. Electrochem. Soc. 153, G1011 (2006)

3. M.B. Joshi, S.L. Hayashi, and M.S. Goorsky, Electrochem. Solid-State Lett. 11, H236 (2008).

4. W.E. Spicer, I. Lindau, P. Pianetta, P.W. Chye, and C.M. Garner, Thin Solid Films 56, 1 (1979).

5. F. Shi, K.-L. Chang, J. Epple, C.-F. Xu, K.Y. Chen, and K.C. Hsieh, J. Appl. Phys. 92, 7544 (2002).

6. C. Lian, H.G. Xing, C.S. Wang, D. Brown, and L. McCarthy, Appl. Phys. Lett. 91, 063502 (2007)

7. M.L. Huang, Y.C. Chang, C.H. Chang, Y.J. Lee, P. Chang, J. Kwo, T.B. Wu, and M. Hong, Appl. Phys. Lett. 87, 252104 (2005).

8. M. Zhu, C.-H. Tung, and Y.-C. Yeo, Appl. Phys. Lett. 89, 202903 (2006)

9. M.S. Carpenter, M.R. Melloch, B. Cowans, Z. Dardas, and W.N. Delgass, J. Vac. Sci. Technol. B 7, 845 (1989).

10. C.J. Sandroff, R.N. Nottenburg, J.C. Bischoff, and R. Bhat, Appl. Phys. Lett. 51, 33 (1987).

11. H. Huang, X. Ren, X. Wang, Q. Wang, and Y. Huang, Appl. Phys. Lett. 88, 061104 (2006).

12. K.D. Choquette, K.M. Geib, H.Q. Hou, A.A. Allerman, S. Kravitz, D.M. Follstaedt, and J.J. Hindi, Wafer Fusion for Integration of Semiconductor Materials and Devices, Report No. SAND99-0923 (1999).

13. K. Nakayama, K. Tanabe, and H.A. Atwater, J. Appl. Phys. 103, 094503 (2008).

14. C.I.H. Ashby, K. Zavadil, A. Howard, and B.E. Hammons, Appl. Phys. Lett. 64, 23882390 (1994).

15. R.S. Bradley, Proc. R. Soc. Lond. A Math. Phys. Sci. 205, 553 (1951).

16. K.R. Zavadil, C.I.H. Ashby, A.J. Howard, and B.E. Hammons, Ultraviolet Photosulfidation of III-V Compound Semiconductors for Electronic Passivation (Orlando, FL, USA: AVS, 1994), p. 1045.

17. A. Plossl and G. Krauter, Mater. Sci. Eng. R Rep. 25, 1 (1999).

18. S. Arabasz, E. Bergignat, G. Hollinger, and J. Szuber, Appl. Surf. Sci. 252, 7659 (2006).

19. S. Adachi, J. Appl. Phys. 58, R1 (1985).

20. N. Liu and T. Kuech, J. Electron. Mater. 34, 1010 (2005).

21. T. Akatsu, A. Plossl, R. Scholz, H. Stenzel, and U. Gosele, J. Appl. Phys. 90, 3856 (2001).

22. F. Shi, S. MacLaren, C. Xu, K.Y. Cheng, and K.C. Hsieh, J. Appl. Phys. 93, 5750 (2003).

23. J.F. Moulder, W.F. Stickle, P.E. Sobol, and K. Bomben, Handbook of X-Ray Photoelectron Spectroscopy, 2nd ed. (Perkin-Elmer Corporation (Physical Electronics), 1992).

24. H. Ouyang, H.-H. Chiou, Y.S. Wu, J. Cheng, and W. Ouyang, J. Appl. Phys. 102, 013710 (2007). 